\title{
EQUILÍBRIO HIDROFÍLICO-LIPOFÍLICO (EHL) DO BIODÍESEL PROVENIENTE DE DO ÓLEO DE MAMONA
}

\author{
D.H.G. PELEGRINE ${ }^{1}$, L.R. CARROCCI ${ }^{2}$
}

${ }^{1}$ Escola de Engenharia de Lorena (EEL/USP), Departamento de Engenharia Química

${ }^{2}$ Faculdade de Engenharia de Guaratinguetá (FEG/UNESP), Departamento de Energia E-mail para contato: dhguima@usp.br

RESUMO - A produção de biocombustíveis obteve grande impulso nos últimos anos, com o aumento do preço dos combustíveis e as preocupações com questões ambientais. Neste contexto, os combustíveis fósseis (diesel e gasolina) são os mais criticados, pois não são biodegradáveis, emitindo poluentes à atmosfera. O biodiesel, por se tratar de um derivado de óleos vegetais, é biodegradável, com baixa emissão de poluentes, sendo considerado o combustível do futuro. Em relação ao diesel, os óleos vegetais são muito mais viscosos. Como tentativa em reduzir a viscosidade destes óleos, a transesterificação dos mesmos tornase viável. Na tentativa de contribuir com a redução da poluição atmosférica, o presente trabalho analisou a reação de transesterificação do óleo proveniente da mamona, pela determinação do EHL, sendo as emulsões preparadas com água, óleo e misturas tenso-ativas (Span 80 e Twen 80). Os ensaios indicaram que a mistura que tinha os melhores resultados, foi aquela com EHL 6,44.

\section{INTRODUÇÃO}

O biodiesel pode ser definido como éster de ácido graxo, renovável e biodegradável, obtido comumente por transesterificação na presença de um catalisador. O biodiesel substitui total ou parcialmente o óleo diesel de petróleo em motores ciclo diesel automotivos (de caminhões, tratores, camionetas, automóveis, etc) ou estacionários (geradores de eletricidade, calor, etc). Pode ser usado puro ou misturado ao diesel em diversas proporções (Azeredo, 2012).

O biodiesel pode ser produzido a partir de qualquer fonte de ácidos graxos, porém nem todas as fontes de ácidos graxos viabilizam o processo a nível industrial. Os resíduos graxos também aparecem como matéria-prima para a produção do biodiesel. Nesse sentido, podem ser citados os óleos de frituras, as borras de refinação, a matéria graxa dos esgotos, óleos ou gorduras vegetais ou animais fora de especificação, ácidos graxos, etc (Costa Neto, 2000; Ferrari et al., 2005).

Com relação à importância econômica da produção do biodíesel, esta pode cooperar com o desenvolvimento econômico de diversas regiões do Brasil, uma vez que é possível explorar a melhor alternativa de matéria-prima, no caso fontes de óleos vegetais tais como óleo de mamona, soja, dendê, girassol, algodão etc, dependendo da região. O consumo do biodiesel e de suas misturas pode ajudar um país a diminuir sua dependência do petróleo, aliado ao fato do petróleo ser um recurso natural não-renovável e o biodiesel, por sua vez, apresentar-se como relevante alternativa de combustível, sendo ele renovável, biodegradável além de gerar alternativas de empregos em áreas geográficas menos propícias para outras atividades econômicas, promovendo assim, a inclusão social (Albuquerque, 2006; Dantas, 2006; Barbosa, 2007). 
A crise do petróleo, nas décadas de 70 e 80 , suscitou diversos estudos referentes à pirólise de triglicerídeos. Na ausência de catalisadores, óleos de soja, dendê, babaçu, pequi, macaúba e canola foram estudados e, mais recentemente, foi demonstrado que a destilação fracionada dos produtos obtidos pelo craqueamento dos óleos de soja e dendê leva aos combustíveis que atendem às especificações do óleo diesel, permitindo seu uso diretamente em motores convencionais (Sharma, 2008; Silva Filho, 2010;).

Ademais, a crescente preocupação da sociedade com questões ambientais deve influir nas decisões dos dirigentes quanto às possibilidades de utilização das fontes energéticas. Dentro deste aspecto, os combustíveis fósseis, tais como o óleo díesel e a gasolina são os mais criticados, devido à produção de uma quantidade de $\mathrm{CO}_{2}$ que o planeta não tem condições de assimilar a longo prazo, causando o chamado efeito estufa, e também pela possibilidade de emissão de óxidos de enxofre. Tais combustíveis pertencem à categoria dos combustíveis não biodegradáveis que, durante o uso dos mesmos, emitem compostos poluentes à atmosfera (Fitzpatrick et al., 2010; Dogaris et al., 2013).

O biodiesel, por se tratar de um combustível derivado de óleos vegetais e gorduras animais, é um combustível biodegradável, com baixa emissão de compostos poluentes na atmosfera, podendo, desta maneira, ser considerado o combustível do futuro (Basha, 2009).

Na tentativa de contribuir com a redução da poluição atmosférica, o presente trabalho propõe analisar a reação de transesterificação do óleo proveniente da mamona.

\section{MATERIAL E MÉTODOS:}

\section{Preparo da Mistura para posterior determinação do EHL}

Para os ensaios prévios e definitivos da preparação das misturas combustíveis foram utilizados os seguintes materiais:

- Óleo diesel automotivo do metropolitano, cujas características são especificadas pela Agencia Nacional do Petróleo (ANP) segundo o Regulamento Técnico ANP No 2/2006 da Resolução ANP $N^{o}$ 15, de 17 de julho de 2006, a qual esta disponível no portal www.anp.gov.br;

- Álcool etílico anidro e hidratado cujas características combustível são especificadas pela ANP segundo o Regulamento Técnico ANP No 7/2005 da Resolução ANP N 36, de 06 de dezembro de 2005, a qual também está disponível no portal www.anp.gov.br;

- Óleo vegetal de mamona

- Tensoativos: Span 80, Tween 80 e dodecil sulfato de sódio;

- Água destilada 
A bancada experimental para a obtenção das misturas combustíveis foi acondicionada no laboratório de Termofluidos do Departamento de Energia da Faculdade de Engenharia Mecânica de Guaratinguetá, FEG-UNESP. Ela consta dos seguintes equipamentos: agitador magnético de 0 a $2000 \mathrm{rpm}$ e controle de temperatura de 0 a $100{ }^{\circ} \mathrm{C}$; balança digital marca Gehaka modelo BK de 0 a $500 \mathrm{~g} \pm 0,001 \mathrm{~g}$; banho termostático com capacidade para 5 litros com resistência elétrica de $1300 \mathrm{~W}$ e controle de temperatura de 0 a $120^{\circ} \mathrm{C}$.

Uma vez definidas as misturas combustíveis, nos próximos 12 meses de vigência do projeto será preciso preparar elas em maiores quantidades que sejam suficientes para a queima na câmara de combustão. Isso será realizado num tanque agitador com capacidade para 40 litros com agitador acionado por um motor elétrico e variador de velocidade.

\section{Determinação do EHL}

Para a construção do diagrama de fases precisa-se primeiro determinar o valor do EHL mais apropriado para fazer as misturas do diagrama de fases. É importante observar que todas as misturas de um diagrama de fases têm o mesmo valor de EHL, o qual é calculado pela soma do EHL de cada um dos óleos multiplicado por sua fração mássica dentro da fase oleosa, de acordo com a seguinte equação:

$$
E H L=\sum X_{i} \cdot(E H L)_{i}
$$

Onde:

$\mathrm{X}_{\mathrm{i}}$ : $\quad$ Fração em massa do composto $\mathrm{i}$

$(\mathrm{EHL})_{\mathrm{i}}: \quad \quad$ Equilíbrio hidroilíco-lipofilíco do composto i

Sendo assim, é preciso conhecer o EHL de cada um dos óleos que conformam as misturas combustíveis do diagrama de fases. Os valores dos EHL do diesel, do óleo refinado de mamona foram determinados seguindo a metodologia descrita por Zanin et al. (2002) e Prista, (2003). Esta metodologia baseia-se no conhecimento que uma emulsão é mais estável quando o EHL da mistura tenso-ativa é igual ao EHL da fase oleosa.

Com o óleo de interesse, água destilada e uma mistura tenso-ativa formada por Span $80(\mathrm{EHL}=4,3)$ e Tween $80(\mathrm{EHL}=15)$, foram preparadas séries de emulsões a temperatura de $45^{\circ} \mathrm{C}$, com valores de EHL do par emulsivo variando em forma escalonada. O valor do EHL da mistura tenso-ativa era variado mudando as proporções de Span 80 e Tween 80. Após 24 horas, todas as emulsões foram examinadas e o valor do EHL do óleo de interesse era o correspondente ao valor de EHL da mistura tenso-ativa que apresentava a emulsão mais estável, isto é da emulsão que não apresentava aspecto turvo nem apresentava separação de fases. 
Para a determinação do EHL do óleo de mamona foram realizados 2 ensaios. No primeiro ensaio as emulsões foram preparadas com a seguinte composição: $10 \%$ de água, 85 $\%$ de soja e $5 \%$ de mistura tenso-ativa.

Tabela 1. Dados da determinação do EHL do óleo refinado de mamona.

\begin{tabular}{|l|l|l|l|l|l|}
\hline \multicolumn{1}{|c|}{ Mistura } & \multicolumn{1}{|c|}{ H2O (g) } & Mamona $(\mathrm{g})$ & Span $80(\mathrm{~g})$ & Tween $80(\mathrm{~g})$ & EHL \\
\hline S1 & 1,0 & 8,5 & 0,475 & 0,025 & 4,84 \\
\hline S2 & 1,0 & 8,5 & 0,450 & 0,050 & 5,37 \\
\hline S3 & 1,0 & 8,5 & 0,425 & 0,075 & 5,91 \\
\hline S4 & 1,0 & 8,5 & 0,400 & 0,100 & 6,44 \\
\hline S5 & 1,0 & 8,5 & 0,375 & 0,125 & 6,98 \\
\hline S6 & 1,0 & 8,5 & 0,350 & 0,150 & 7,50 \\
\hline S7 & 1,0 & 8,5 & 0,327 & 0,173 & 8,00 \\
\hline S8 & 1,0 & 8,5 & 0,304 & 0,200 & 8,58 \\
\hline S9 & 1,0 & 8,5 & 0,280 & 0,220 & 9,00 \\
\hline
\end{tabular}

\section{RESULTADOS E DISCUSSÕES:}

Os resultados referentes aos dados da Tabela 1 são apresentados na Figura 1.

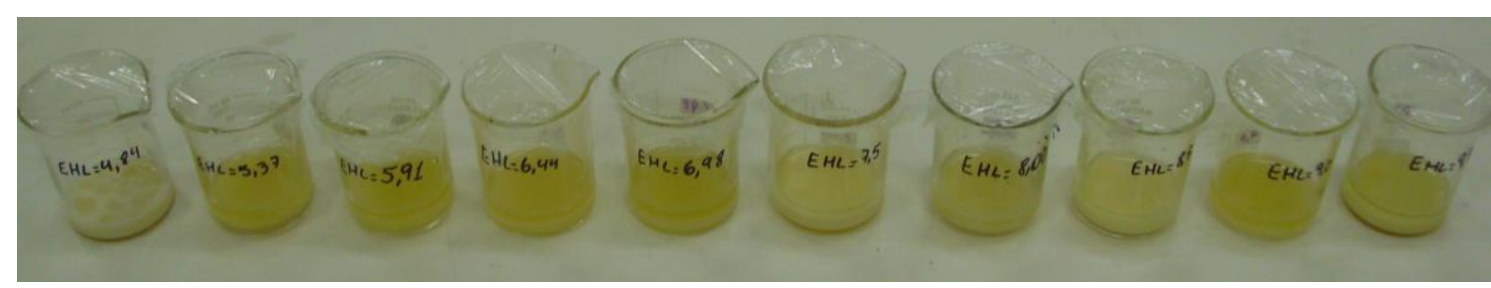

Figura 1: Resultados do EHL do óleo de mamona, para diferentes concentrações dos tenso ativos Span 80 e Tween 80 . 
Os dois ensaios para o óleo de mamona indicaram que a mistura que tinha os melhores resultados, isto é, que se apresentou como uma única fase uniforme foi aquela com EHL 6,44.

\section{CONCLUSÃO}

Os melhores resultados foram alcançados com EHL 6,44.

\section{REFERÊNCIAS}

ALBUQUERQUE, G.A.; CONCEIÇÃO, M.M.; SILVA, M.C.D.; SANTOS, I.M.G.; FERNANDES,V.J.; SOUZA, A.G. Avaliação reológica e caracterização físico-química do biodiesel de canola e misturas. In: Anais do Congresso da Rede Brasileira de Tecnologia de Biodiesel, Brasília. RTBT, 175-179, 2006.

AZEREDO, V.B.S. Produção de biodiesel a partir do cultivo de microalgas: estimativa de custo e perspectivas para o Brasil. Dissertação (Mestrado em Planejamento Energético, Universidade Federal do Rio de Janeiro. 2012. 171f.

BARBOSA, A.L.P.B. Biodiesel de mamona em trator agrícola na operação de preparo do solo. Tese (Doutorado em Engenharia Agrícola). Universidade Estadual Paulista. 2007. $75 f$.

BASHA, S.A.; GOPAL, K.R.; JEBARAJ, S. A review on biodiesel production, combustion, emissions and performance. Renewable and Sustainable Reviews, 13, 1628-1634, 2009.

COSTA NETO, P.R.; ROSSI, L.F.S.; ZAGONEL, G.F.; RAMOS, L.P. Produção de biocombustível alternativo ao óleo diesel através da transesterificação de óleo de soja usado em frituras. Química Nova, São Paulo, 23(4), 531-537, 2000.

DANTAS, M.B. Obtenção, caracterização e estudo termoanalítico de biodiesel de milho. Dissertação (Mestrado em Química), Universidade Federal da Paraíba, João Pessoa. 2006. $205 \mathrm{f}$.

DOGARIS, I.; GKOUNTA, O.; MAMMA, D.; KEKOS, D. Bioconversion of dilute-acid pretreated bagasse to etanol by Neusorpora crassa. Applied Microbiology and Biotechnology, 95(2), 541-550, 2013.

FITZPATRICK, M.; CHAMPAGNE, P.; CUNNIGHAM, M.F.; WHITNEY, R.A. A biorrefinary processing perspective: treatment lignocellulosic materials for the production of value-add products. Bioresource Technology, 101(23), 8915-8922, 2010.

FERRARI, A.R.; OLIVEIRA, V.S. SEABIO, A. Biosiesel de soja - taxa de conversão em ésteres etílicos, caracterização físico-química e consumo em gerador de energia. Química Nova, 28(1), 19-23, 2005. 
SHARMA, S.K. MULVANEY, S.J. RIZVI, S.S.H. Food processing engineering: theory and laboratory experiments. United States of America: Wiley-Interscience. 348p. 2000.

SILVA FILHO, J.B. Produção de biodiesel etílico de óleos e gorduras residuais (ogr) em reator químico de baixo custo. Dissertação (Mestrado em Engenharia Mecânica e de Materiais), Universidade Tecnológica Federal do Paraná. 2010. 57 f. 